\title{
Trading Places: Industrial Specialization in the European Union*
}

\author{
MARIUS BRÜLHART \\ School of Economic Studies, University of Manchester, \\ Manchester M13 9PL, England
}

\begin{abstract}
This article examines the location of manufacturing industries in the European Union. It draws on intra-industry trade measures for 1961-90 and on sectoral employment data by countries and regions. The analysis of employment data suggests that EU industry has become increasingly localized in the 1980s. Increasing-returns industries are strongly concentrated at the economic core of the EU and display low levels of intra-industry trade. High-tech industries are also strongly localized, but show no centre-periphery gradient and no specific pattern of intra-industry trade. The main potential for future specialization appears to remain in sectors sensitive to labour costs, which are still relatively dispersed and have high levels of intra-industry trade. Employment in these industries is shifting towards the EU periphery. 'Neoclassical' determinants of international specialization are thus likely to dominate the ongoing adjustment process in EU manufacturing.
\end{abstract}

* I am grateful to Robert Elliott, Dermot McAleese, Johan Torstensson, Paul Walsh and an anonymous referee for valuable comments. Part of the research was financed by the Stimulation Plan for Economic Sciences of the European Union (SPES-CT91-0058). 


\section{Introduction}

There is a strong consensus among economists that a fall in trade costs increases aggregate welfare. International competition and specialization increase efficiency in production and enhance consumption opportunities, and thus result in net gains of combined producer and consumer surplus. This is the basic economic rationale behind the successive steps of economic integration in the European Union (EU), from the signing of the Treaty of Rome in 1957 to the implementation of the single market programme and progression towards Economic and Monetary Union.

The distribution of these overall welfare gains, however, is subject to an ongoing theoretical and empirical debate. A central issue in this context is the geographical location of manufacturing industry. ${ }^{1}$ Due to locational advantages, countries might specialize into certain industries, while others specialize out of these industries. Both groups of countries may still be net gainers in terms of combined producer and consumer surplus, but the industry-specific welfare gains are greater for the countries specializing into a particular sector. The increase in EU regional transfers agreed in 1992 implies that policy-makers have recognized the potentially uneven distributive effects of the single market programme.

Current theoretical analysis of these issues can be categorized into two broad schools of thought: neoclassical models and 'new' theories of trade and economic geography. Neoclassical analysis assumes constant returns to plant scale and perfectly competitive markets, and it determines the location of industrial activity by the accessibility of immobile production factors and output markets. There are no technological spillovers and, assuming that factors and consumers are spread out in space, a geographically dispersed structure of industrial production is predicted. In contrast, the 'new' theories, which incorporate increasing returns and imperfectly competitive markets, mostly conclude that economic integration promotes the concentration of industries in central locations.

This article investigates the pattern of industrial specialization among EU countries. It thereby sheds light on the relevance of recent developments in trade and location theory. As integration progresses, the principal question is whether EU industry concentrates around an industrial core (which can be central or peripheral in terms of geography), or whether its growth is dispersed evenly among the Member States. Such trends are not expected $a$ priori to affect all

\footnotetext{
${ }^{1}$ Note that this is a study of industry location, not of income convergence, among the countries or regions of the European Union. For an analysis of convergence of EU countries, see Ben-David (1993). Neven and Gouyette (1995), Fagerberg and Verspagen (1996) and Quah (1996) have studied convergence among EU regions. Industry-by-industry studies of specialization have so far been confined to analyses of individual countries (e.g. Hine, 1989, on Spain), and rarely to the entire EU. Exceptions are Helg et al. (1995) and De Nardis et al. (1996), both of which are based on less disaggregated data than the present article.
} 
industrial sectors symmetrically. Thus, the analysis is carried out on a disaggregate set of industries.

It is attempted to make some progress on what Krugman $(1994$, p. 26) has described as 'the disappointing state of empirical work on the new trade theory'. ${ }^{2}$ The article also updates the much discussed study by Hufbauer and Chilas (1974), who were puzzled about the low levels of industrial specialization among the countries of the then EEC in comparison to the degree of locational concentration of industry in the United States.

The article is organized in four parts. Section II summarizes the theoretical priors and defines the relevant concepts. Section III examines sectoral specialization trends among EU countries using indices of intra-industry trade. Section IV discusses centre-periphery patterns of intra-industry trade among EU countries. The trade analysis is complemented in Section V by a study of the sectoral distribution of employment across EU countries and regions. The main findings are summarized in the Conclusions.

\section{Trade and Location: Theory and Concepts}

\section{The Theory of Trade and Location}

It has long been recognized that trade and location are 'two sides of the same coin' (Isard, 1956, p. 207). However, a successful merger of trade and location theory, where the former incorporates typical features of the latter such as externalities and imperfect competition, has occurred only in recent years under the label 'new economic geography'. A useful survey of this literature has been compiled by Ottaviano and Puga (1997), and we therefore limit this overview to a categorization of the most prominent models and a summary of their hypotheses and predictions.

Two principal schools can be distinguished: neoclassical models and the 'new' theories of trade and geography. ${ }^{3}$ Neoclassical theory explains location and trade as a function of exogenous characteristics of regions and countries. When trade is liberalized, regions and countries specialize according to their comparative advantage, which is determined by differences in technology or in factor endowments. If, for a certain industry, there are no relevant differences across locations and trade costs are non-zero, then constant returns and perfect competition will lead to a locational dispersion of this industry. Given the high degree of industrial specialization observed among very similar regions and

\footnotetext{
${ }^{2}$ A recent survey of empirical research on trade and industry location is given in Brülhart (1998).

${ }^{3}$ A terminology which labels both schools as new, even though their main contributions are separated by almost a century, is obviously unfortunate; and it is to be hoped that a better heading will be found for the recent generation of models.
} 
countries, this traditional approach evidently does not capture all relevant determinants of industry location.

Neoclassical economists have long recognized that there are specialization forces which are independent from country endowments. Marshall (1920) has shown that the spatial concentration of firms - even with constant returns to scale - can increase efficiency by pooling non-material inputs such as industryspecific labour and supporting services, and by facilitating technological spillovers. ${ }^{4}$ Localized technological spillovers in particular are often identified as one of the main forces for sectorial clustering. Technological externalities are an intuitively plausible phenomenon, but they are immeasurable, and the calibration of theoretical models therefore becomes entirely arbitrary.

The 'new' models of trade and economic geography use pecuniary externalities as a force for industrial concentration. In imperfectly competitive markets with non-zero trade costs, a firm's profits are affected by the geographical proximity of other firms, be they competitors, suppliers or customers. In the "new trade theory' all goods enter final consumption, factors are immobile across countries, and factor prices are equalized (Krugman, 1980). Such a highly stylized configuration produces crisp predictions: industry (which produces differentiated goods under monopolistic competition) will become more concentrated in one country the larger is the scope for scale economies and the lower are trade costs. This concentration of industry will occur in the country with the larger domestic demand. The implication is that economic integration will produce a shift of increasing-returns activity towards large countries.

The 'new economic geography' relaxes some of the stringent assumptions of the 'new' trade models. One class of models, based on the seminal paper by Krugman (1991b), assumes that labour is internationally mobile and shows that a reduction of trade costs can lead two initially perfectly identical countries to develop into an industrial core and a periphery. The process at work is 'cumulative causation' through changes in market size induced by migrating labour. However, these models describe what must be very long-term developments, and appear relatively far removed from the European reality of low labour mobility. The second class of 'new economic geography' models seems more relevant. Venables (1996) considers a setting with internationally immobile labour but with input-output linkages among firms. This model also produces concentration of industry in one country when trade costs between two initially identical countries are reduced. The strength of concentration forces is directly related to the strength of linkages and the potential for scale economies in industry.

\footnotetext{
${ }^{4}$ Note that efficiency gains from pooled inputs are effectively the result of scale economies in the provision of intermediary goods.
} 
Not all models of the 'new economic geography', however, predict a monotonically positive relationship between economic integration and industrial concentration. If one allows for endogenous changes in factor prices, then both the labour-mobility and the input-output-linkage models are shown by Puga (1996) to produce a u-shaped relationship between the share of industry retained by the periphery and the level of integration. At early stages of integration, concentration forces dominate and industry clusters in the larger country; but below a critical threshold of trade costs, further integration favours a redispersion of some industrial activity towards the periphery, attracted by lower factor costs.

In a nutshell, theory offers three fundamental explanations for industrial concentration: proximity to input factors, localized non-pecuniary externalities, and market size effects in scale-sensitive industries. In isolation, these forces all produce a more clustered industrial geography when trade costs are lowered. Yet, in combination, these forces may be offsetting. The 'u-curve' detected in several variants of 'new economic geography' models is an example where market-size effects and factor abundance work in opposite ways. The clarity of the predictions generated by most of these models, as well as the indeterminacy introduced by combinations among them, call for empirical verification.

\section{Some Definitions}

For empirical analysis, the terms 'industry', 'specialization' and 'concentration' require precise definition. In most models of the 'new' theories, only two sectors are distinguished: increasing-returns 'industry' and constant-returns 'agriculture'. The standard neoclassical setting considers two industries, intensive in labour and in capital respectively. The defining criterion for products categorized in an 'industry' is that they share identical production technologies. In reality, of course, production technologies across products are rarely identical, hence the delineation of 'industries' becomes arbitrary to an extent. There is a tendency among empirical researchers to strive for the greatest possible number of separate industries, hence to seek the most sectorally disaggregated data, since this maximizes the likelihood that an industry contains truly similar products. The use of sectorally disaggregated statistics, however, implies a departure from the two-sector world of most theoretical models. Empirical work thus reinterprets the 'new' theories, which model the agglomeration of manufacturing as a whole, in a cross-sectional sense, as an explanation of the concentration of individual manufacturing (or other increasing-returns) sectors. Reassuringly, the theoretical consideration of two manufacturing industries (Krugman and Venables, 1996) or a continuum of industries (Fujita et al., 1998), does not affect the fundamental results found in two-sector settings. Hence, empiricists' multisector interpretation of two-sector models appears justifiable. 
Industries can be either dispersed or concentrated/clustered/localized. In the cross-country dimension, concentration of industries translates into the specialization of countries. But what defines the size of an industry in a particular place? Empirically most meaningful are measures such as employment, output or valueadded. If production technologies are identical across locations, these measures are equivalent. However, the use of production-related measures generally precludes a high degree of sectoral disaggregation, since industrial census data tend to be compiled in relatively broad product categories. For greater disaggregation, empirical researchers draw on trade data. Trade statistics have the advantage of distinguishing up to several thousand 'industries'. The disadvantage of trade data is that they are available only at country level, not for regions; and that trade flows are not necessarily a reliable proxy for industry size in terms of production variables. This study therefore draws on both trade and production data.

The counterpart of 'industry concentration', in the terminology of economic geography, is 'inter-industry specialization' in the vocabulary of trade economists. If export propensities are correlated across products within each industry, then inter-industry specialization correlates with inter-industry trade, which in turn is the inverse of intra-industry trade (IIT). IIT for a group of industries $i=1 \ldots n$ is traditionally measured using an index attributed to Grubel and Lloyd (1975):

$$
I I T=\frac{\sum_{i=1}^{n}\left|X_{i}-M_{i}\right|}{\sum_{i=1}^{n}\left(X_{i}+M_{i}\right)}
$$

where $M_{i}$ and $X_{i}$ represent imports and exports of a particular industry. This index takes values between 0 , for complete inter-industry trade, and 1 , for complete intra-industry trade. It can be calculated for bilateral trade flows, or for trade between one country and a group of partners; and it can be summed across industries, after weighting by trade shares. ${ }^{5}$

\section{Intra-Industry Trade and Industry Characteristics}

We start the empirical analysis with an exploration of IIT patterns, in order to exploit the higher level of sectoral disaggregation provided by trade statistics compared to census data.

\footnotetext{
${ }^{5}$ For a discussion of the statistical properties of the Grubel-Lloyd index, see Greenaway and Milner (1986). In line with common practice, IIT indices were not adjusted for aggregate trade imbalance. The case against such adjustments has been stated most recently by Vona (1991). An anonymous referee suspected that the non-linear nature of the IIT index complicates intertemporal comparisons. This is a serious problem for comparing magnitudes of IIT changes. Hence, we concentrate on the sign of changes in the index.
} 


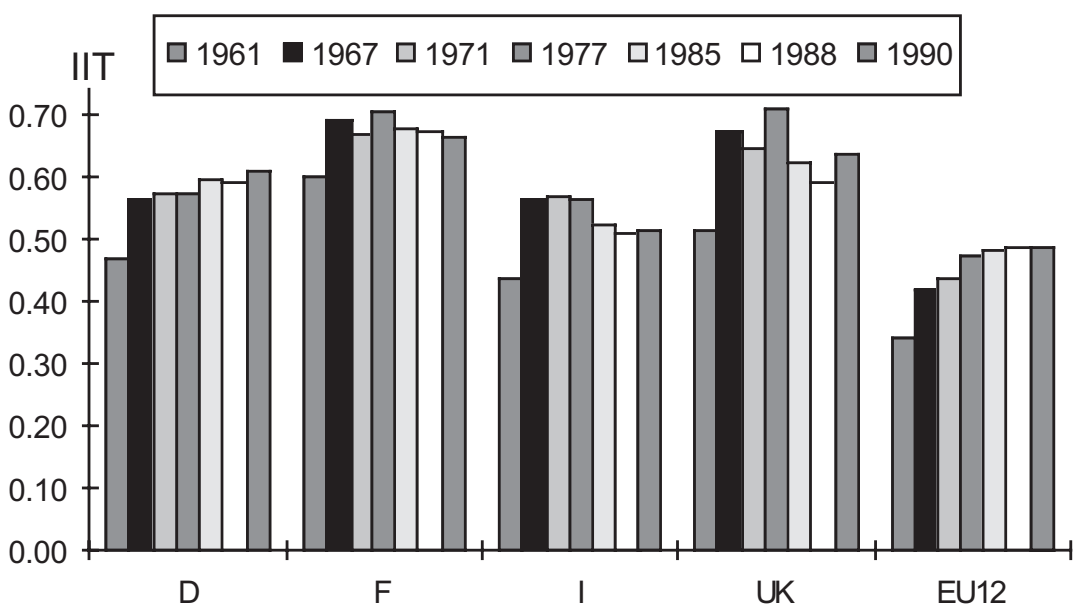

Figure 1: Intra-EU IIT in Manufactured Goods, 1961-90

Notes: Calculated from SITC 4-digit $(1961,67)$ and 5-digit $(1972,77,85,88,90)$ trade data (unweighted avrages of 4/5-digit figures aggregated to SITC Rev. 13 -digit level, see Appendix).

Figure 1 confirms that IIT is a real and significant phenomenon. In 1990, when the SITC product nomenclature distinguished 2,398 industrial product groups, 51.6 per cent of intra-EU manufactures trade was IIT. The fact that very similar goods are exchanged among countries - against the predictions of most neoclassical trade theory - is thus a significant empirical fact.

Figure 1 also shows that the general rise of IIT observed in virtually all industrialized countries throughout the post-war era has in some instances slowed down, and even started to decline, during the 1980s. ${ }^{6}$ While the weighted average of intra-EU IIT in manufactured products was still on the increase (not shown in Figure 1), the unweighted average, calculated over 98 SITC 3-digit product groups remained roughly stable between 1985 and 1990. Three major EU economies, France, Italy and the UK, displayed stagnating or decreasing IIT trends. ${ }^{7}$

\section{Scale Economies}

As a first step in the analysis of intra-EU IIT developments, we investigate the effect of increasing returns on both the levels and trends of the IIT index. For this purpose, 94 industries of our SITC 3-digit data set are allocated to one of three

\footnotetext{
${ }^{6}$ On the post-war rise in intra-EU IIT and the importance of European integration, see Greenaway (1987). The first analysis to detect a stagnation of IIT growth was Greenaway and Hine (1991).

${ }^{7}$ Similar trend reversals have occurred in Denmark and Ireland. Information on the data and methods used throughout this article is provided in the Appendix.
} 
categories of scale economies: HIGH, INTERMEDIATE and LOW. ${ }^{8}$ This three-way partition is based on a study by Pratten (1988, pp. 2-70), where manufacturing industries are ranked 'in order of the importance of economies of scale for spreading development costs and for production costs'. The classification is based on two criteria: engineering estimates of the minimum efficient plant scale relative to the industry's output, and estimates of the cost gradient below the minimum efficient scale. This ranking is based not only on observed plant size, but also on the (unexploited) potential for scale economies. There is thus a clear correspondence between this empirical classification and the theoretical concept of internal scale economies. ${ }^{9}$

The results reported in Figure 2 are unweighted averages of IIT coefficients in SITC 3-digit industries, originally calculated at the 4- and 5-digit levels. Two features of the plotted IIT trends are noteworthy.

First, industries with low scale economies appear to exhibit consistently higher levels of IIT than industries with intermediate or high economies of scale. This phenomenon runs counter to much of the common understanding of factors underlying IIT, but it confirms the predictions of the 'new' trade theory, whereby some interval of decreasing costs is necessary for the emergence of IIT (which is true for nearly all industrial activities), but, as this interval grows beyond some lower threshold, IIT levels decline. ${ }^{10}$

Closer scrutiny of the data at the level of individual industries confirms the plausibility of this result. Among the industries in the HIGH category with lowest average IIT levels we find fertilizers (SITC 561), railway rolling stock (731), dyeing materials $(531,532)$ and motor cars $(732)$. These are likely increasingreturns sectors. Note also that we have excluded ferrous and non-ferrous metals from the HIGH category, even though the iron and steel industries are often quoted as typical increasing-returns sectors. We have chosen to attribute them to the INTERMEDIATE category, because they have a strongly 'Ricardian' or 'Weberian' nature, in the sense that proximity to natural resources is a dominating locational determinant. ${ }^{11}$ Hence, low IIT in the HIGH industries probably cannot be explained by a coincidence of increasing returns with materialsoriented sectors.

\footnotetext{
${ }^{8}$ Four of the 983 -digit industries could not be allocated to any of the sectors contained in the list by Pratten (1988) (see Appendix).

${ }^{9}$ Note that the Pratten (1988) classification distinguishes 20 industries. These are bound to be subject to considerable intra-industry heterogeneity in terms of underlying production requirements. Our data set is thus likely to conceal considerable differences within 'industries'. Currently available statistics, however, do not allow a more disaggregated analysis.

${ }^{10}$ Ray (1991, p. 169) has detected the same pattern in the United States, where IIT 'occurs predominantly in product lines in which efficient production is small-scale'.

${ }^{11}$ Figure 4 shows that resource-oriented sectors display IIT patterns which are very similar to those exhibited by the scale-sensitive industries.
} 


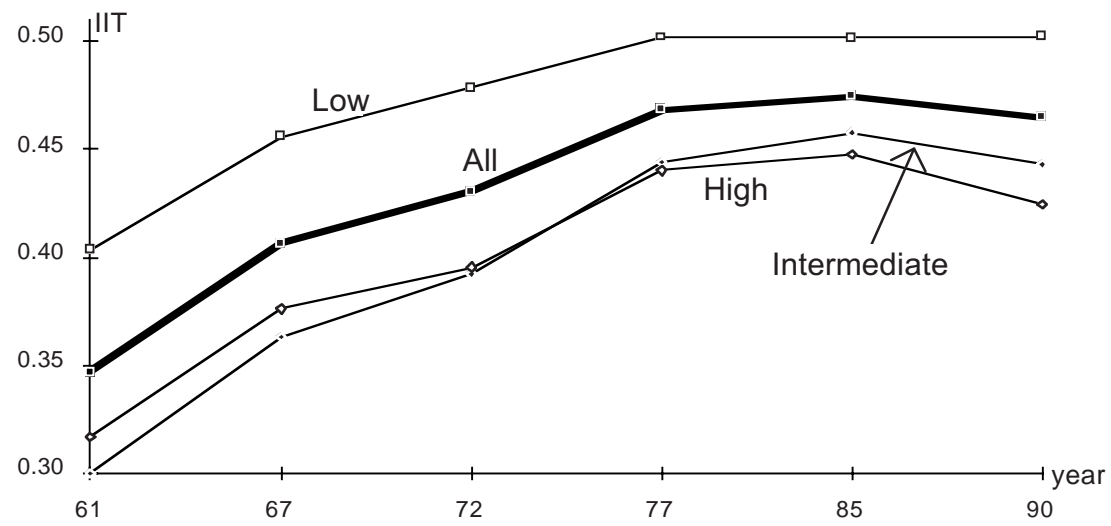

Figure 2: IIT Trends and the Importance of Scale Economies

Note: Classification of industries according to Pratten (1988).

Second, Figure 2 indicates that the reversal of the IIT trend occurred earlier where increasing returns are important. IIT in the sectors of the HIGH category stagnated between 1977 and 1985, while the trend break in the INTERMEDIATE group occurred after 1985, and the LOW category experienced continued IIT growth until 1990. This pattern could reflect a process of industrial specialization fuelled by the exploitation of scale economies in the run-up to the single market.

\section{Statistical Significance}

The validity of these results might be called into doubt for a number of reasons. For instance, the difference between the averages of the three industry categories might be purely random. This would be the case if variances within categories were high relative to the differences between the calculated means. Analysis of variance (ANOVA) indicates that the differences between the categories HIGH and INTERMEDIATE are indeed not statistically significant. ${ }^{12}$ However, the differences between the means of all three categories are significant at the 1 per cent level for all years except 1977 and 1985. This suggests that the difference between the LOW category and the two other groups is significant, and that the widening of IIT disparities between 1985 and 1990 was not a random event.

Another problem might be caused by the increase in the number of base industries over the sample period. Higher sectoral disaggregation biases measured IIT downwards (Greenaway and Milner, 1986). Hence, the trends depicted in Figure 2 could be due to a disproportionate rise in the number of underlying industries in the HIGH and INTERMEDIATE categories. We have tested this

\footnotetext{
${ }^{12}$ The results can be obtained from the author upon request.
} 
possibility by calculating the ratio between the number of base industries in 1961 (SITC Revision 1, 4-digit level) and the number of base industries in 1990 (SITC Revision 3, 5-digit level), separately for each category. The increase in the total number of manufacturing product groups from 365 in 1961 to 2,169 in 1990 is reflected in the high values of our calculated ratios. In the LOW category, the number of base industries was 5.29 times higher in 1990 than in 1961, in the INTERMEDIATE category, this ratio was 7.29, and in the HIGH category it stood at 4.46. While the rate of increase in product disaggregation was highest in the INTERMEDIATE category, it was lower in the HIGH group than in the LOW category. Therefore, at least for the industries with high scale economies, increased statistical disaggregation cannot be the cause of stagnating IIT growth. However, the small magnitude of intertemporal variations as well as the small number of data points warrant a cautious treatment of this result.

Our calculations based on the product categorization by Pratten (1988) thus seem to have yielded statistically significant results. Nevertheless, they ought to be treated with caution. First, many 3-digit product groups are heterogeneous amalgams of goods with considerably different underlying production requirements. Hence, any categorization according to certain production characteristics is bound to be somewhat arbitrary. Second, industry categories according to the importance of scale economies could happen to coincide with other distinguishing factors which might be a more important determinant of IIT patterns. One way of double-checking our results is to apply alternative categorizations and to compare the results with those obtained here. This will be undertaken in the following paragraphs.

\section{Technology}

As discussed in Section II, a widely discussed though empirically elusive aspect of external scale economies are technological spillovers among firms producing sophisticated innovative products. If there were strong forces for the spatial clustering of high-technology industries, observed IIT in these sectors should be relatively low.

We have tested this proposition, by identifying 13 out of our 98 sample industries as 'high-tech', following the classification suggested in Eurostat (1989), which earmarks these sectors based on the ratio of R\&D expenditure to industry turnover. Figure 3 reports the average IIT indices for both categories, as well as the IIT average for the four industries which belong to the high-tech category and are also sensitive to scale economies (category HIGH).

The results reported in Figure 3 do not conform to expectations based on theories predicting a locational clustering of high-technology industries. Indeed, average intra-EU IIT in high-tech products has been higher than the overall mean for most of our sample period, which indicates above average geographical 


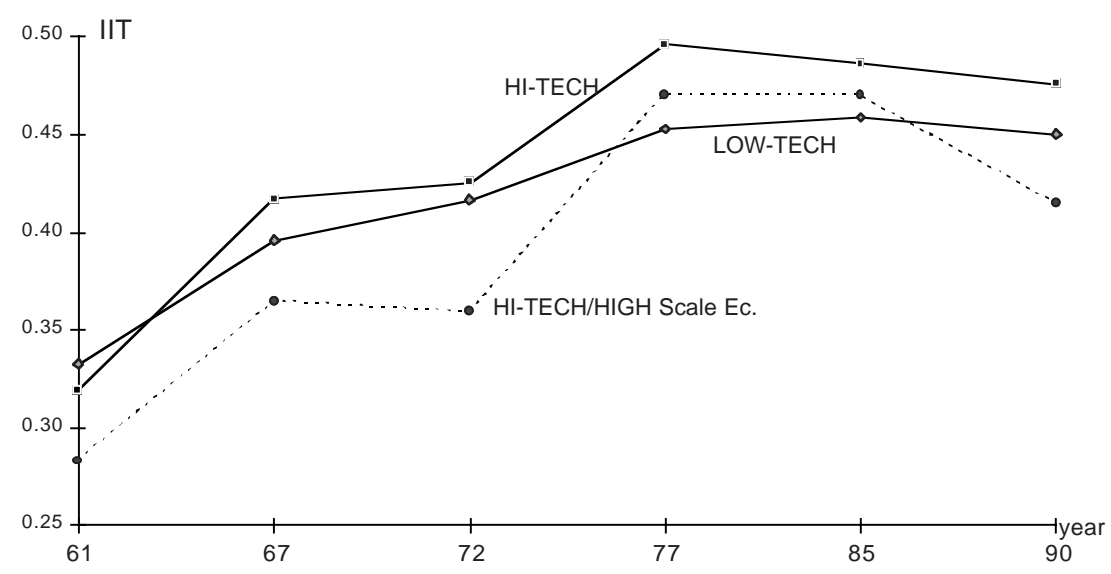

Figure 3: IIT Trends and 'High-Technology' Industries

Note: Classification of industries according to Eurostat (1989) and Pratten (1988).

dispersion of these sectors. Only where advanced technology and high internal scale economies interact do the expected IIT patterns emerge. A robust interpretation of these results, however, is impossible, since none of the differences in IIT means is statistically significant (ANOVA). This analysis therefore suggests no systematically different intra-EU patterns of IIT for high-tech industries. ${ }^{13}$

\section{Other Industry Characteristics}

Instead of categorizing sectors according to a single aspect of the production process, researchers at the OECD (1987) have grouped all manufacturing industries 'on the basis of the primary factors affecting the competitive process in each activity'. Five categories are distinguished:

1. 'resource-intensive' industries, where the main competitive factor is 'access to abundant natural resources' (19 product groups of our sample);

2. 'labour-intensive' industries, where the main competitive factor is labour costs (22 product groups);

3. 'scale-intensive' industries, where the main competitive factor is the 'length of production runs' (26 product groups);

4. 'differentiated goods', where the main competitive factor is 'tailoring products to highly varied demand characteristics' (14 product groups);

\footnotetext{
${ }^{13}$ Our results confirm doubts over the importance of technological spillovers for industrial concentration voiced by Krugman (1991). At the same time, his caveat with regard to empirical studies also applies to this analysis: 'The fact that the classification scheme is ... antiquated means that quite small traditional industries still rate their own three-digit codes, while advanced sectors are buried in meaningless aggregates' (Krugman, 1991, p. 59). Note that our IIT data set is classified according to SITC Revision 1, where, for example, mechanical typewriters are assigned to the same 3-digit group as desktop computers, and video recorders share a product group with harpsichords.
} 


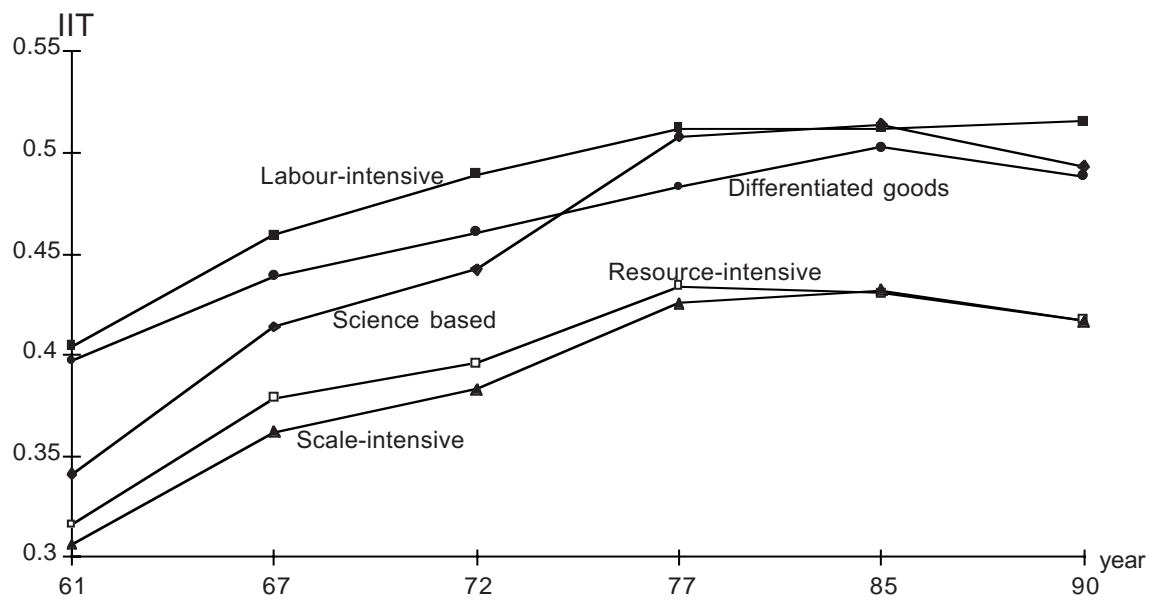

Figure 4: IIT Trends in Five Industry Categories

Note: Classification of industries according to OECD (1987).

5. 'science-based' industries, where the main competitive factor is 'rapid application of scientific advance' (17 product groups).

This categorization does not overlap perfectly with the commodity categories applied above, but the similarities are reassuring. Twelve of the 13 Eurostat (1989) 'high-tech' industries are also part of the OECD's 'science-based' product category, and of the OECD's 26 'scale intensive' industries, 23 belong to the HIGH and INTERMEDIATE categories of our classification based on Pratten (1988).

Figure 4 reports the calculated intra-EU IIT averages for the five industry categories. These results are in line with our previous findings. First, they confirm the below-average shares of IIT in the industries characterized by high scale economies, as well as the IIT growth reversal. All six IIT averages of the

Table 1: ANOVA F-Ratios Underlying Figure 4

\begin{tabular}{lllllll}
\hline Industry Categories & 1961 & 1967 & 1972 & 1977 & 1985 & 1990 \\
\hline Resource-intensive & 2.6 & 2.2 & 2.6 & 2.7 & $4.6^{*}$ & $5.2^{*}$ \\
Labour-intensive & $9.5^{* *}$ & $9.4^{* *}$ & $9.3^{* *}$ & $4.9^{*}$ & $4.2^{*}$ & $9.0^{* *}$ \\
Scale-intensive & $7.0^{* *}$ & $8.8^{* *}$ & $7.6^{* *}$ & $6.4^{*}$ & $6.4^{*}$ & $8.4^{* *}$ \\
Differentiated goods & 3.9 & 1.9 & 1.3 & 0.3 & 1.3 & 1.2 \\
Science-based & 0.1 & 0.1 & $0.2^{* *}$ & 2.9 & 3.3 & 2.0 \\
All & $5.0^{* *}$ & $4.6^{* *}$ & $4.3^{* *}$ & $3.5^{*}$ & $4.2^{* *}$ & $5.6^{* *}$ \\
\hline
\end{tabular}

*** significant at the $1 \%$ level, ${ }^{*}$ significant at the $5 \%$ level.

(c) Blackwell Publishers Ltd 1998 
'scale-intensive' category are significantly different from the total sample mean (ANOVA, see Table 1). Second, high-technology industries again do not appear to exhibit specific IIT patterns; the divergence between the category averages and the total sample mean are statistically insignificant in all six years.

Two interesting new findings emerge from this analysis. First, resourceintensive industries are subject to below average IIT. Even though the results for these sectors are statistically significant only for 1985 and 1990, they are in line with the expectation that 'Ricardian' goods give rise mainly to inter-industry specialization and trade. Second, labour-intensive industries exhibit consistently the highest IIT levels. These results are statistically significant, and they go against the theoretical prediction that such 'Heckscher-Ohlin' goods lead to inter-industry trade.

Grouped analysis of intra-EU IIT has cast doubts on two dominant aspects of conventional wisdom with regard to IIT. On the one hand, our findings run against the assumption that there is a positive relationship between the intensity of scale economies and IIT. This, of course, lends support to the 'new' theories, which generally predict this negative relationship. On the other hand, we find that IIT is higher in industries where production costs typically depend on the availability of factors such as (unskilled) labour. It could be hypothesized that this reflects simply a delayed process of inter-industry specialization in these sectors, and that IIT levels are bound to fall in these industries sooner or later. ${ }^{14}$

\section{Intra-Industry Trade and Peripherality}

The low levels of the IIT index in sectors subject to high scale economies might reflect a centripetal process of industrial concentration as suggested by many of the 'new' trade and geography models, while high IIT in labour-intensive sectors could result from a process of industrial dispersion in these industries. Furthermore, the absence of significantly distinct IIT patterns in the high-technology sectors might suggest that these industries are not, as many have feared, concentrating in Europe's economic core.

To investigate these aspects we now consider intra-EU IIT levels for each Member State separately, relating them to the country's relative location in terms of economic geography.

\section{Centrality and Peripherality of EU Countries}

If we want to analyse the trade patterns of countries in terms of their location relative to the economic core regions, each country has to be assigned some

${ }^{14}$ Brander (1981) and Davis (1995) have offered theoretical approaches which generate IIT even in homogenous goods; the former through international oligopolistic interaction and the latter by assuming different technologies across countries. Our findings support such alternatives rather than the standard scenario of the "new" theories based on monopolistic competition. 
coefficient value indicating its market size. This has to be an inexact procedure, since the factors determining economic distance are different for various industries, and since regions within one country can vary considerably in terms of economic distance from the market core. Nevertheless, it seems plausible that significant and systematic differences in terms of geographical market access exist even across the EU countries.

The accessibility of 166 EU NUTS-level II regions has been evaluated by Keeble et al. (1986) using the following centrality index: ${ }^{15}$

$$
P_{i}=\sum_{j} \frac{Y_{j}}{D_{i j}}+\frac{Y_{i}}{D_{i i}} ; \quad i \neq j
$$

where $i$ is the relevant region, $j$ stands for all other EU regions, $Y_{i, j}$ is 1983 regional gross domestic product, $D_{i j}$ measures the shortest road distance ${ }^{16}$ between the largest settlements in regions $i$ and $j$, and $D_{i i}$, the 'intra-regional distance cost', defined as 'one-third of the radius of a circle of the same area as region $i$ '. We have aggregated these indices for the 12 EU countries, weighting them by 1983 regional population. The calculated values are listed in Table 2.

Note that this empirical exercise is inspired by a multi-industry interpretation of the theoretical models, distinguishing several industries. We would therefore ideally avail ourselves of centrality indices constructed on the basis of regional expenditure in each of the industries. Such data are unavailable. Hence, we have to make the assumption that expenditure shares of our sample industries are stable across countries (and regions in Section IV). Given the similarity of incomes and preferences across EU countries, this assumption does not appear excessively restrictive. However, if we were to consider not just final consumer demand, but also demand for intermediate products, as in the Venables (1996)

Table 2: Centrality Indices for EU Countries

\begin{tabular}{llcclc}
\hline Rank & Country & Index Value & Rank & Country & Index Value \\
\hline 1 & Belgium & 10,252 & 7 & Italy & 5,873 \\
2 & Netherlands & 9,805 & 8 & Denmark & 4,721 \\
3 & West Germany & 9,546 & 9 & Ireland & 3,617 \\
4 & United Kingdom & 8,931 & 10 & Spain & 3,522 \\
5 & France & 8,000 & 11 & Portugal & 2,648 \\
6 & Luxembourg & 7,857 & 12 & Greece & 2,293 \\
\hline
\end{tabular}

\footnotetext{
${ }^{15}$ Keeble et al. (1986) have referred to this coefficient as the 'peripherality index'. Since this measure relates negatively to the peripherality of a region, we term it 'centrality index' for clarity.

${ }^{16}$ Where regions are separated by water, weighted values of ferry costs were applied.

() Blackwell Publishers Ltd 1998
} 
model, then the assumption becomes strong, since the concentration of a particular industry endogenously enlarges demand for some of its output. Given the degree of industry concentration in the EU, reported below, this effect might be significant.

It might be argued that the analysis is flawed because it does not take account of shifts in relative peripherality over time. However, there are strong indications that the relative market size of European countries and regions has remained remarkably stable. Begg and Mayes (1994) have recalculated centrality indices of the EU regions for 1977, 1983, 1985, 1989 and 1990, using the Keeble methodology, and they detected only marginal changes over time. It thus seems acceptable to apply unchanged centrality indices for the different years of our data samples.

\section{Intra-Industry Trade and Centrality}

The centrality indices were combined with the IIT data set in order to test for centre-periphery gradients underlying the IIT patterns detected in Section II. We have computed correlation coefficients between, on the one hand, the values of the centrality index and, on the other hand, IIT and changes in IIT. This exercise was conducted for all manufacturing industries as well as separately for each of the categories based on the Pratten (1988) and OECD (1987) classifications. The results are reported in Table 3.

The positive relationship between centrality and IIT, detected in many previous studies, emerges clearly from the coefficients reported in the top half of Table 3.17 Central EU countries tend to exhibit considerably higher levels of IIT than peripheral countries. Calculated for the entire set of manufacturing sectors, as well as for our various sub-categories, this relationship has remained roughly stable between 1961 and 1990 .

In 1990, IIT was still higher in central countries than at the EU periphery, but the gap had narrowed since 1961. This is the main message conveyed by the correlation coefficients reported in the lower part of Table 3, and it applies to all industry sub-categories. Consistently negative and statistically significant coefficients mean that IIT generally increased more (or decreased less) where the centrality index was low. This finding could reflect a process of industrial dispersion towards the periphery leading to an increase in IIT of peripheral countries, as their trade in originally net importing sectors became gradually more balanced.

Rising IIT at the periphery, however, does not necessarily signify a shift from deficit to balanced sectoral trade. It can also reflect a narrowing of sectoral trade surpluses, and the reverse evidently applies to falling IIT (at the core). Hence, there is no straightforward interpretation of the correlations reported in the lower

\footnotetext{
${ }^{17}$ Econometric analyses of the 'determinants' of IIT have been surveyed by Greenaway and Milner (1986). 
Table 3: Intra-Industry Trade, Centrality and Dominant Industry Characteristics (Correlation Coefficients) $^{a}$

\begin{tabular}{lccc}
\hline & \multicolumn{2}{c}{ Correlation IIT - Centrality Index } \\
& 1961 & 1977 & 1990 \\
\hline All industries & 0.62 & 0.62 & 0.63 \\
Scale economies: & & & \\
$\quad$ HIGH & 0.62 & 0.68 & 0.62 \\
INTERMEDIATE & 0.65 & 0.63 & 0.71 \\
LOW & 0.61 & 0.60 & 0.57 \\
Main competitive factor: & & & \\
$\quad$ Resource-intensive & 0.59 & 0.56 & 0.57 \\
Labour-intensive & 0.59 & 0.57 & 0.56 \\
Scale-intensive & 0.65 & 0.67 & 0.66 \\
Differentiated goods & 0.63 & 0.61 & 0.65 \\
Science-based & 0.65 & 0.66 & 0.72 \\
\hline
\end{tabular}

Correlation $\triangle I I T^{b}-$ Centrality Index

\begin{tabular}{lccc} 
& $1961-77$ & $1977-90$ & $1961-90$ \\
\hline All industries & -0.33 & -0.46 & -0.50 \\
Scale economies: & & & \\
$\quad$ HIGH & -0.37 & -0.50 & -0.51 \\
$\quad$ INTERMEDIATE & -0.32 & -0.47 & -0.52 \\
$\quad-0.33$ & -0.42 & -0.42 \\
$\quad$ LOW & & & \\
$\quad$ Resource-intensive & -0.34 & -0.39 & -0.46 \\
$\quad$ Labour-intensive & -0.30 & -0.40 & -0.44 \\
$\quad$ Scale-intensive & -0.33 & -0.50 & -0.51 \\
$\quad$ Differentiated goods & -0.40 & -0.49 & -0.55 \\
$\quad$ Science-based & -0.36 & -0.45 & -0.55 \\
\hline
\end{tabular}

Notes: ${ }^{a}$ All coefficients are statistically significant at the $0.01 \%$ level $(t$ test).

$b^{b} \Delta \mathrm{IIT}=\left(\mathrm{IIT}_{t}-\mathrm{IIT}_{t-n}\right) /\left(0.5 *\left\{\mathrm{IIT}_{t}+\mathrm{IIT}_{t-n}\right\}\right)$, where $t$ is the last and $t-n$ the first year of the period.

half of Table 3. Take, for instance, the strongly negative relationship between DIIT and the centrality index in the HIGH category. This indicates that the growth (decline) in IIT was more (less) pronounced at the periphery than in the central countries. Intuitively, one might conclude that this reflects a catching-up of the periphery in industries subject to high scale economies, thus reducing their sectoral trade deficits. However, the negative correlation coefficient could also reflect the exact opposite pattern, where industrial concentration of the HIGH 
category in the economic core regions further increased. In this scenario, sectoral trade surpluses of the central countries widen, IIT falls, and, given a not-toorapid decline of IIT at the periphery, the correlation index turns out negative. It is this indeterminacy in the interpretation of IIT changes which has led to the development of various measures of marginal IIT. ${ }^{18}$ Unfortunately, we cannot avail ourselves of a comprehensive set of such data for the EU, hence we cannot resolve the ambiguity left by the analysis of IIT changes without referring to production figures. ${ }^{19}$

\section{The Spatial Distribution of Industrial Employment in the EU}

The relative scarcity of production and employment figures compared to the detailed coverage of trade statistics forces us to conduct the locational analysis at a considerably higher level of statistical aggregation. In most of what follows, we distinguish 18 NACE 2-digit industries. Similar to the IIT analysis, we shall first investigate overall specialization patterns and, in a second step, describe the centre-periphery structures.

\section{Industrial Specialization}

In order to capture the degree of concentration or dispersion of EU industrial sectors, we have calculated locational Gini indices measuring the locational structure of manufacturing employment, as suggested by Krugman (1991b). These indices can take values between 0 and 1 . The higher the Gini index, the stronger is the locational divergence between the particular industry and manufacturing overall. A high Gini index thus suggests a high degree of inter-industry specialization. Where the Gini index is (close to) zero, a sector is not localized, but spread out in line with total manufacturing employment. The latter situation could reflect both intra-industry specialization, where countries exchange different varieties of similar products, or it could occur in non-traded sectors, where the same industry exists in each country to serve its home market. ${ }^{20}$

Table 4 reports locational Gini indices for the distribution of 18 industries among 11 EU countries. ${ }^{21}$ One result to note is that industrial agglomeration and specialization in Europe appears to have increased significantly during the 1980s. First, total manufacturing employment has become more agglomerated, relative to the distribution of population among the EU Member States. This can be verified in the last row of Table 4, which shows a 21 per cent increase of the

\footnotetext{
${ }^{18}$ The measure of interest in the present context would be the $B$ index developed in Brülhart (1994).

${ }^{19}$ The SPES data set contains only Grubel-Lloyd indices. In order to compute a comprehensive set of marginal IIT measures for the EU, one would need to have access to the underlying bilateral trade statistics.

${ }^{20}$ The calculation of locational Gini indices is described by Krugman (1991).

${ }^{21}$ A comparable exercise has been conducted by Helg et al. (1995). They report Gini indices for eight EU industries in 1975, 1980 and 1990. Most of their results are broadly in line with ours. However, they identify 
Table 4: Dispersion of Industrial Employment in the EU, 1980 and 1990

\begin{tabular}{|c|c|c|c|c|c|c|c|c|}
\hline \multirow[t]{3}{*}{$N A C E$} & \multirow[t]{3}{*}{ Industry Description } & \multicolumn{2}{|c|}{$\begin{array}{r}\text { Employment } \\
\text { Share (\%) }\end{array}$} & \multicolumn{3}{|c|}{$\begin{array}{c}\text { Locational } \\
\text { Gini Coefficients }\end{array}$} & \multicolumn{2}{|c|}{ Specialization $^{a}$} \\
\hline & & (1) & $(2)$ & (3) & (4) & (5) & (6) & (7) \\
\hline & & 1980 & 1990 & 1980 & 1990 & $\begin{array}{l}\text { 1980-90 } \\
(\% \text { change })\end{array}$ & $\begin{array}{l}\text { Highest } \\
\text { (1990) }\end{array}$ & $\begin{array}{l}\text { Lowest } \\
\text { (1990) }\end{array}$ \\
\hline 43 & Textiles & 6.2 & 4.9 & 0.106 & 0.170 & 60 & $\mathrm{P}$ & NL \\
\hline 45 & Clothing/footwear & 5.7 & 5.1 & 0.096 & 0.148 & 54 & $\mathrm{P}$ & NL \\
\hline 44 & Leather goods & 0.5 & 0.5 & 0.150 & 0.212 & 42 & I & DK \\
\hline 48 & Rubber/plastics & 4.0 & 4.9 & 0.174 & 0.226 & 29 & $\mathrm{~F}$ & $\mathrm{P}$ \\
\hline $25 / 6$ & Chemicals & 7.2 & 7.8 & 0.178 & 0.230 & 29 & NL & $\mathrm{P}$ \\
\hline 22 & Metals & 5.4 & 3.6 & 0.188 & 0.242 & 29 & $\mathrm{~B}$ & IRL \\
\hline 35 & Motor vehicles & 8.2 & 8.3 & 0.270 & 0.344 & 28 & $\mathrm{D}$ & GR \\
\hline 34 & Electrical engineering & 11.2 & 12.0 & 0.254 & 0.316 & 25 & $\mathrm{D}$ & GR \\
\hline 36 & Other transport equipment & 3.8 & 3.4 & 0.238 & 0.288 & 21 & UK & IRL \\
\hline 24 & Non-metallic minerals & 5.0 & 4.5 & 0.100 & 0.122 & 20 & $\mathrm{P}$ & $\mathrm{D}$ \\
\hline 31 & Misc. metal articles & 9.3 & 9.6 & 0.192 & 0.228 & 19 & $\mathrm{E}$ & IRL \\
\hline 32 & Mechanical engineering & 10.2 & 10.5 & 0.320 & 0.370 & 15 & DK & GR \\
\hline 33 & Office/data proc & 0.8 & 1.2 & 0.312 & 0.328 & 5 & IRL & $\mathrm{P}$ \\
\hline 49 & Misc. manufacturing & 1.1 & 1.1 & 0.194 & 0.198 & 2 & DK & $\mathrm{P}$ \\
\hline 46 & Timber/furniture & 4.2 & 4.1 & 0.206 & 0.202 & -2 & $\mathrm{E}$ & IRL \\
\hline 37 & Instrument engineering & 1.4 & 1.5 & 0.402 & 0.392 & -3 & IRL & GR \\
\hline 47 & Paper/printing & 5.8 & 6.5 & 0.208 & 0.192 & -7 & NL & $\mathrm{D}$ \\
\hline $41 / 2$ & Food/drink/tobacco & 10.0 & 10.6 & 0.176 & 0.162 & -8 & IRL & $\mathrm{D}$ \\
\hline & All & 100.0 & 100.0 & 0.156 & 0.188 & 21 & $\mathrm{D}^{b}$ & $\mathrm{GR}^{b}$ \\
\hline
\end{tabular}

Notes: ${ }^{a}$ Specialization ratio $=\left(\left\{E_{i j} / \sum_{j} E_{i j}\right\} /\left\{\sum_{i} E_{i j} / \sum_{i} \sum_{j} E_{i j}\right\}\right)$, where $E_{i j}$ denotes employment in the manufacturing sector $i$ of EU country $j$.

$b$ Based on the ratio between the share in EU manufacturing employment and the share in EU population.

Gini index for overall manufacturing between 1980 and 1990. Second, within total manufacturing the indices suggest a considerable amount of inter-industry specialization, since the Gini index increased in 14 out of our 18 sectors.

Having observed that, in the 1980s, aggregate EU manufacturing has become increasingly agglomerated, it is interesting to analyse how this general tendency is reflected in the specialization patterns of individual industries. At the top of the

the 'textile, wearing apparel and leather' industry as the most localized, which is diametrically opposed to our finding. This points to the sensitivity of such results to categorical aggregation and statistical accuracy. The fact that our calculations are based on more disaggregated sectoral data supports the results obtained here. 
list of Table 4 (which is in decreasing order of the percentage change in Gini coefficients) appear three related sectors: textiles, clothing and footwear, and leather goods. These industries appear at the bottom of the industry ranking by economies of scale in Pratten (1988), and are attributed in OECD (1987) to the 'labour-intensive' (textiles, clothing) and 'resource-intensive' (leather goods) categories. In the 1980s, the most powerful force for industrial specialization in the EU thus seems to have been the 'classical' exploitation of lower factor costs. However, Table 4 also suggests that scale economies have driven some of the increased specialization. The industries with highest potential scale economies according to Pratten (1988), namely motor vehicles, other vehicles, and chemicals, appear in the top half of our list, all displaying above-average increases in localization. No clear impact of high technological requirements emerges once again. According to both OECD (1987) and Eurostat (1989), typical high-tech sectors are chemicals, data processing and instrument engineering. There are wide differences in the localization trends of these industries. For instance, while localization of the chemicals sector increased quite considerably, the employment pattern in the instrument engineering sector dispersed slightly. ${ }^{22}$

If we consider absolute levels of the Gini indices instead of their change over time, a quite different picture emerges. All high-technology sectors are among the most localized. The industries characterized by high scale economies also figure in the top half of an industry ranking by Gini index. The three sectors with the most significant increases in localization (textiles, clothing, leather), however, were still among the most dispersed industries by 1990 .

Columns (1) and (2) of Table 4 show that the three particularly factorsensitive industries at the top of the list accounted for a declining share of EU manufacturing employment (12.4 per cent in 1980, 10.5 per cent in 1990). The three typically scale-sensitive industries account for a roughly stable proportion of manufacturing employment (19.2 per cent in 1980, 19.5 per cent in 1990), while the three high-tech sectors expanded their share of EU manufacturing jobs from 9.4 per cent in 1980 to 10.5 per cent in 1990.

The story emerging from these summary calculations is that much of the scale and technology driven localization process in the EU has already taken place, while specialization induced by factor endowments is only starting to gather steam. Interestingly, the locational Gini indices calculated for the United States by Krugman (1991, p. 58) present a starkly different picture: 'The thing that leaps out from the table is not the localization of high technology industries, but the

${ }^{22}$ It should be remembered that our data are highly aggregated, and that they might conceal increased localization of some more narrowly defined high-technology sectors. Furthermore, even if we could obtain more disaggregate sectoral statistics, it might be near impossible to disentangle the different stages in the production process of multinational firms. If, say, a computer firm develops new software in its Italian plant and manufactures blank diskettes in its French subsidiary, the employment in both plants is likely to enter the same statistical category, even though the former is evidently more knowledge intensive. 
cluster of textile-related industries'. After its long history as an economically integrated area, the American economy has produced some highly localized sectors. Apart from some well-known industry clusters such as aircraft in Seattle and silicon valley in California, the group of most highly localized industries consists of many traditional labour and resource-intensive sectors such as carpets, hats, handbags and jewellery. If the American experience is a suitable yardstick, a considerable amount of further inter-industry specialization has to be expected in the EU; not in the high-technology and increasing-returns industries, but in traditional sectors where factor endowments dominate the localization process.

\section{Industry Location and Centrality}

Having investigated the general specialization patterns in the EU, we now analyse the centre-periphery dimension of these findings. Some preliminary comments in this respect can be derived from Table 4. Columns (5) and (6) list the countries which are specialized most and least strongly in the particular sectors, compared to the other EU countries. The last row of Table 4 shows that, in terms of overall manufacturing employment, Germany, at the EU's economic core, is most strongly specialized, whereas the population share of manufacturing employment is smallest in Greece, the Union's most peripheral member. On the other hand, localization has increased most over our sample period in industries which are most important for relatively peripheral countries (Portugal, Italy).

The results of a somewhat more sophisticated analysis of the aggregate industrial centre-periphery pattern are reported in Table 5. The upper part of the table contains coefficients of correlation between, on the one hand, the share of manufacturing employment by country, and, on the other hand, the centrality indices of Table 2, both for 1980 and for 1990. As expected, the share of population engaged in manufacturing employment is positively related to a country's centrality. No significant relationship emerges between centrality and the change in the relative sizes of manufacturing sectors in the 11 countries.

However, entire countries are ill-suited locational units on which to base our analysis. First, they are few in number, so that they provide us with a very limited set of observations and, second, they differ greatly in size and structure, so that it must be assumed that intra-country differences in economic accessibility in many instances exceed inter-country differentials. We have therefore supplemented our analysis by calculations on a regional data set. No regional employment figures were available for the EU's southern periphery - Greece, Portugal and Spain - and the numbers of regions covered within the remaining sample of nine EU countries varied considerably among industrial sectors. Regional centrality indices could be taken straight from Keeble et al. (1986). 
Table 5: Centre-Periphery Structure of Total EU Manufacturing (Coefficients of Correlation with Centrality Index, NACE 2-4)

\begin{tabular}{|c|c|c|}
\hline \multicolumn{3}{|c|}{11 EU Countries, $1980-90^{a}$} \\
\hline Industrial Employment ${ }^{b} 1980$ & O Industrial Employment ${ }^{b} 1990$ & Change $^{b} 1980-90$ \\
\hline $0.62^{*}$ & $0.60^{*}$ & 0.08 \\
\hline \multicolumn{3}{|c|}{86 EU Regions, 1973-89 } \\
\hline Industrial Employment ${ }^{b} 1973$ & Industrial Employment ${ }^{b} 1989$ & Change $e^{c} 1973-89$ \\
\hline $0.39^{* * *}$ & $0.30 * *$ & $-0.20^{*}$ \\
\hline
\end{tabular}

Notes: ${ }^{a}$ EU 12 excluding Luxembourg.

${ }^{b}$ Share of NACE 2-4 employees in total population.

$c$ Change in the share of NACE 2-4 employees in total population as a proportion of the initial level. Statistical significance $\left(t\right.$ tests): $0.01 \%:{ }^{* * *}, 2 \%:^{* *}, 10 \%:^{*}$.

Regional correlation indices for employment shares of total manufacturing are reported in the lower part of Table 5. (Note that the regional calculations for 1973 and 1989 cover a wider time span than the computations based on country data.) The regional correlation indices confirm the finding that manufacturing employment is agglomerated in the central EU areas. In addition, the analysis of regional data suggests that the degree of this concentration has diminished since 1973. The intensity of the positive correlation was significantly lower in 1989 , and the correlation between changes in the share of industrial employment and the centrality index was negative. Hence, the gap in the size of regional manufacturing sectors between the core and the periphery appears to have narrowed. This result does not contradict the finding of increased localization of aggregate industry, reported in the bottom row of Table 4. Apart from the fact that different time periods are covered, the results can be perfectly compatible, since increased localization does not have to be concentrated at either pole of the centre-periphery spectrum. ${ }^{23}$ It thus seems that, while inter-industry specialization continues, the centre-periphery distinction is losing some of its importance for the location of manufacturing activity.

We have also investigated the centre-periphery structure of EU manufacturing at a sectoral level, again using data for NACE 2-digit industries. Table 6 lists

\footnotetext{
${ }^{23}$ As an illustrating example, imagine a world of three regions, $P$ (periphery), $I$ (intermediate) and $C$ (core), and three equally sized economic sectors, $m$ (manufacturing), $s$ (services) and $a$ (agriculture). Each region has the same population and income, and the distance separating $I$ and $P$ is equal to the distance between $I$ and $C$. In the initial year, there is some $m$ in all three regions, but $(m /\{m+s+a\})_{C}>(m /\{m+s+a\})_{I}>(m /$ $\{m+s+a\})_{P}$. The initial Gini index is thus relatively low, and the correlation between centrality and the share of manufacturing is high. If, by the time of the final year, $P$ has specialized entirely in $a, I$ has concentrated exclusively on $m$, and $C$ provides only $s$, then the locational Gini index will have increased to the maximum value of 1 , while the correlation index between industry share and centrality will have fallen to zero.
} 
Table 6: Centre-Periphery Structure of Some EU Manufacturing Sectors (Coefficients of Correlation with Centrality Index)

\begin{tabular}{|c|c|c|c|c|c|c|c|c|}
\hline \multirow[b]{3}{*}{$N A C E$} & \multirow[b]{3}{*}{ Description } & \multicolumn{3}{|c|}{11 EU Countries } & \multicolumn{4}{|c|}{ EU Regions } \\
\hline & & Empl. ${ }^{a}$ & Empl. $^{a}$ & $\Delta$ Empl. $^{b}$ & Empl. $^{a}$ & Empl. ${ }^{a}$ & $\Delta$ Empl. $^{b}$ & \\
\hline & & 1980 & 1990 & 1980-90 & 1976 & 19851 & $1976-85$ & Obs. ${ }^{c}$ \\
\hline $25 / 6$ & Chemicals & $0.77^{* *}$ & $0.75^{* *}$ & 0.20 & $0.31^{* *}$ & $0.23^{*}$ & $-0.24^{*}$ & 80 \\
\hline 33 & Office/data & 0.15 & -0.05 & -0.18 & 0.16 & 0.09 & $-0.32^{*}$ & 34 \\
\hline 35 & Motor veh. & $0.60^{*}$ & $0.63^{*}$ & 0.25 & $0.40^{* * *}$ & $0.39^{* * *}$ & $* * 0.01$ & 72 \\
\hline 37 & Instrument engineering & 0.17 & -0.01 & $-0.59^{*}$ & 0.09 & 0.13 & 0.14 & 70 \\
\hline 43 & Textiles & $-0.64^{*}$ & $-0.60^{*}$ & -0.20 & 0.14 & -0.09 & $-0.37^{* * *}$ & $* 88$ \\
\hline 44 & Leather goods & $-0.63^{*}$ & -0.42 & 0.03 & $-0.32^{* *}$ & $-0.28^{* *}$ & -0.05 & 65 \\
\hline 45 & Clothing/footwear & $-0.79^{* *}$ & $-0.74^{* *}$ & $-0.58^{*}$ & $-0.19^{*}$ & $-0.42^{* * *}$ & $*-0.32^{* *}$ & 76 \\
\hline
\end{tabular}

Notes: ${ }^{a}$ Sector share in total manufacturing employment of country/region.

$b$ Change in the sectoral employment share as a proportion of the initial level.

${ }^{c}$ Number of regions for which data were available (regions in EU 12 excl. E, GR and P). statistical significance $\left(t\right.$ tests): $0.01 \%:^{* * *}, 2 \%:^{* *}, 10 \%:{ }^{*}$

the correlations computed for 7 of the 18 sectors at the level of both countries and regions. For reasons of data availability, the regional analysis was conducted for the years 1976 and 1985.

Comparing Table 6 with Table 4 , we find three broad types of industries. The first type is highly localized (high Gini) and concentrated at the EU's core (strong positive correlation). This configuration applies to the chemicals and the motor vehicles sectors - both are typically scale-sensitive industries. A second type of industry is relatively dispersed (low Gini) but represents a significantly higher share of total manufacturing employment in peripheral regions (strong negative correlation). The textile-related industries fit into this category. Third, there appears to be a type of sector which is highly localized (high Gini) but is not clustered at either the centre or the periphery (weak correlation). This pattern applies to the sectors of office and data processing, and instrument engineering, which are both attributed to the high-technology category.

If we look at the changes in the centre-periphery structure of manufacturing sectors, Table 6 supports the conclusion that the locational centre-periphery gradient in the EU is diminishing. In most industries of our sample, the absolute value of the correlation coefficient fell, and most correlation coefficients between the centrality index and changes in the sectoral employment share are negative. The results of Table 6 do not suggest a further concentration in the central regions of the increasing-returns industries, which are already highly clustered at the EU core. They do, however, indicate a further concentration of 
activities in the textile-related industries at the periphery. For the high-tech sectors, there is some indication of dispersion towards the periphery.

\section{Conclusions}

This article has reported the patterns of industrial specialization in the EU against the background of recent advances in trade and location theory. Four principal sets of findings emerge.

First, the degree of industrial specialization among EU countries has increased in the 1980s. This is manifested in a rise in locational Gini indices. EU industries appear to be clustering, as predicted inter alia by Hufbauer and Chilas (1974). Such a process is likely to be a source of aggregate welfare gains, but it can cause considerable adjustment costs. Increased specialization is a corollary of economic integration in the majority of trade and geography models; hence this finding cannot be taken as a validation of any particular theory. Note, however, that our finding of increased industrial clustering is not convincingly supported by trade data. Recent research suggests that IIT among EU countries increased in the early 1990s (Brülhart, 1998).

Second, it is found that industries characterized by strong internal scale economies are localized at the EU core. These industries also display relatively low intra-industry trade and a stagnation in the growth of such trade in the 1980s. These findings support the relevance of the 'new' trade and geography models.

Third, labour-intensive industries are found to be relatively dispersed over the area of the EU. They also display high levels of intra-industry trade. Yet, it is in these sectors that the strongest trend towards increased localization is detected, as labour-intensive activities are concentrating at the EU periphery. Since, overall, these are relatively declining sectors, the detected relocation must reflect particularly high job losses at the EU core. The increase in localization, however, started from relatively low levels, so that geographical concentration of these sectors was still below average in 1990. It seems plausible to assume that this observation explains to some extent why increased localization of production has not yet led to a decrease of IIT in the labour-cost sensitive sectors. There appears to remain much potential for specialization driven by input costs and input requirements, so that inter-industry trade seems poised to re-emerge in these sectors. This scenario would gain particular relevance if the EU were to extend its internal trading regime to some of its eastern neighbours. The strongest driving forces for future industrial specialization, therefore, are likely to be 'neoclassical' factor-cost considerations, and not the exploitation of scale economies emphasized by the 'new' theories.

Fourth, according to employment data, high-tech industries in the EU are highly localized, but not along a centre-periphery gradient. However, this 
finding is not reflected in trade data, as no distinct IIT patterns were found for technology-intensive sectors. These ambiguous findings lend scant support to models which predict the formation of technology clusters based on localized informational spillovers or on the importance of pooled markets for skilled labour. ${ }^{24}$

The findings of this article are subject to inevitable statistical limitations. The industry definitions used in statistical classifications are often broader than the theoretical concept of a technologically homogenous industry. On the part of explanatory variables, we are limited to qualitative information, which does not allow a parametric analysis. Our exercise has to assume implicitly that the relative degrees of increasing returns across industries do not change over time, since no data are available on changes in minimum efficient plant scales. Furthermore, time and geographical coverage differ for the various parts of our analysis. Another difficulty arises from the limited usefulness of traditional IIT indices for the analysis of changes in specialization over time. It would thus be desirable to supplement this study in due course by a more disaggregated investigation of sectoral employment patterns and by an analysis of marginal IIT.

\section{Appendix: Data Sources and Transformations}

The main statistical source for our empirical analysis is the IIT database created by the participants of the SPES research network on 'Trade, Specialisation and Market Structure in the EC' between 1992 and 1994. This database contains Grubel-Lloyd indices for $11 \mathrm{EU}$ countries (Belgium and Luxembourg form one trading entity). The indices are calculated separately for total, intra-EU and non-EU trade for the years 1961, 1967, 1972, 1977, 1985 and 1990. Adjustment of IIT indices for aggregate trade imbalances was not undertaken, due to the lack of theoretical justification of such transformations (Vona, 1991). The distinctive feature of these indices compared to previous research results is that they are calculated from highly disaggregated trade data, namely SITC 4-digit figures for 1961 and 1967 and SITC 5-digit figures for 1972 to 1990. The underlying trade statistics were provided by the OECD.

In the SPES database, the IIT indices are aggregated to and reported at the SITC 3digit level. Since the SITC product classification was revised twice over the period covered in our study, we rearranged all the SPES indices into SITC Revision 1 product groups, based on United Nations (1961, 1986), so that changes in the IIT indices over time could be tracked industry by industry. Since this article is concerned with the manufacturing sector, we retained only the indices pertaining to SITC Sections 5 to 8 . Thus an IIT data set for intra-EU trade in 98 industries was compiled.

\footnotetext{
${ }^{24}$ Locational dispersion of high-tech sectors is not necessarily synonymous with similar industrial performance of geographical regions. Significant variation of productivity levels might persist among different subsectors and firms. Lawrence (1987), for instance, found considerable differences in aggregate industrial performance of European countries in spite of a remarkable similarity in the distribution of the shares of industrial sectors in total manufacturing output.
} 
In Figure 1, the trade-weighted averages for France, Italy and the United Kingdom are based on summary IIT indices for SITC 5-8 as calculated by the SPES researchers. The EU average is the unweighted mean of the indices calculated for the 11 sample countries.

In order to calculate the results reported in Figure 2, four of the 98 industries of our data set had to be eliminated, because they could not be allocated to any of the three categories of scale economies. The eliminated industries are (SITC Group in brackets): fur skins (613), pearls and precious stones (667), developed cinematographic film (863) and works of art (896). The categories are based on the 'Ranking of Manufacturing Industry Groups by Economies of Scale' in Pratten (1988, pp. 2-70). Our HIGH category contains the first four of the 20 industries in Pratten's table (motor vehicles, other vehicles, chemicals and man-made fibres). Our INTERMEDIATE category consists of the sectors ranked 5 to 9 in Pratten (1988) (metals, office machinery, mechanical engineering, electrical engineering and instrument engineering). The remaining 11 industries identified by Pratten (1988) constitute the LOW category. Since the industries in Pratten's table are based on the NACE classification, they had to be identified among our SITC sectors using a NACE-SITC concordance table. 20 SITC industries were attributed to the HIGH category, 33 to the INTERMEDIATE category and 41 to the LOW category. An analysis of variance on the null hypothesis that the differences between the three category averages reported in Figure 2 are random yielded the following $F$-ratios: 16.3 (1961), 13.2 (1967), 9.2 (1972) 3.9 (1977), 2.7 (1985) and 6.5 (1990). The relevant critical values are 3.1 (5 per cent level) and 4.9 (1 per cent level).

The high-tech industries underlying the analysis of Figure 3 are listed in Eurostat (1988) according to SITC Rev. 2 5-digit product headings. Based on this list, we identified the following 13 industries of our IIT data set as high-tech sectors (SITC group in brackets): radioactive materials (515), medicinal and pharmaceutical products (541), plastic materials (581), chemical materials n.e.s. (599), non-electric power generating machinery (711), office machines (714), electric power machinery and switch gear (722), telecommunications apparatus (724), electro-medical and radiological apparatus (726), other electrical machinery and apparatus (729), aircraft (734), scientific instruments and apparatus (861), and watches and clocks (864). The four sectors which belong to both this set of high-tech industries and to the HIGH category of scale economies are SITC groups 515, 541, 599 and 734. An analysis of variance on the null hypothesis that the differences between the high-tech and the 'low-tech' category averages reported in Figure 3 are random yielded the following $F$-ratios: 0.2 (1961), 0.5 (1967), 0.1 (1972) 1.9 (1977), 0.8 (1985) and 0.8 (1990). The relevant critical value at the 5 per cent confidence level is 3.9 .

Underlying Figure 4 is the classification in ISIC 2-digit and 3-digit product groups compiled by the OECD (1987, p. 283). The results of our analysis of variance on the calculated category means are reported in Table 1.

The centrality indices listed in Table 2 are calculated from the regional indices reported by Keeble et al. (1986). We chose the indices adjusted by the authors for purchasing-power parity exchange rates and aggregated them for each country, weight- 
ing the indices by 1983 regional population taken from Eurostat regional statistics.

For the correlation analysis reported in Table 3, five of the 98 industries were dropped from the original IIT data set. These were the four sectors which could not be attributed to any of the three categories based on Pratten (1988) as well as SITC Group 515 (radioactive materials), for which the country coverage of our IIT data set is very patchy. Thus, the reported correlations are based on 1,023 observations (93 industries, 11 countries) for each of the three sample years.

The employment figures for the 18 NACE sectors underlying the results of Table 4 were taken from Eurostat's annual industrial structure statistics. Gaps in these data were filled with estimates based largely on industry statistics published by the OECD. Sectoral employment figures could be compiled for 11 EU countries. Not enough data were available for Luxembourg.

The same statistical sources apply to the correlation coefficients reported in the upper half of Table 5, where sectoral employment figures are summed for each countries, and the correlations thus relate to only 11 observations. The results listed in the lower half of Table 5 and in Table 6 are calculated from regional employment figures published as part of Eurostat's regional statistics.

\section{References}

Begg, I. and Mayes, D. (1994) 'The Implications of Peripherality for Northern Ireland'. Northern Ireland Economic Council, Report 111, Belfast.

Ben-David, D. (1993) 'Equalizing Exchange: Trade Liberalization and Income Convergence'. Quarterly Journal of Economics, Vol. 108, pp. 653-79.

Brander, J. (1981) 'Intra-Industry Trade in Identical Commodities'. Journal of International Economics, Vol. 11, pp. 1-14.

Brülhart, M. (1994) 'Marginal Intra-Industry Trade: Measurement and Relevance for the Pattern of Industrial Adjustment'. Weltwirtschaftliches Archiv, Vol. 130, pp. 600-13.

Brülhart, M. (1995) 'Scale Economies, Intra-Industry Trade and Industry Location in the New Trade Theory'. Trinity Economic Papers, No. 95/4, Trinity College, Dublin. Brülhart, M. (1998) 'Economic Geography, Industry Location and Trade: The Evidence'. The World Economy, Vol. 21, forthcoming.

Davis, D. R. (1995) 'Intraindustry Trade: A Heckscher-Ohlin-Ricardo Approach'. Journal of Intenational Economics, Vol. 39, pp. 201-26.

De Nardis, S., Goglio, A. and Malgarini, M. (1996) 'Regional Specializaion and Shocks in Europe: Some Evidence from Regional Data'. Weltwirtschaftliches Archiv, Vol. 132, pp. 197-214.

Eurostat (1989) Statistical Analysis of Extra-EUR 12 Trade in Hi-Tech Products. Theme 6, Series D, Luxembourg.

Fagerberg, J. and Verspagen, B. (1996) 'Heading for Divergence? Regional Growth in Europe Reconsidered'. Journal of Common Market Studies, Vol. 34, pp. 431-48. Fujita, M., Krugman, P. and Venables, A. (1998) The Spatial Economy: Cities, Regions and International Trade, MIT Press, forthcoming. 
Greenaway, D. (1987) 'Intra-Industry Trade, Intra-Firm Trade and European Integration'. Journal of Common Market Studies, Vol. 26, pp. 153-72.

Greenaway, D. and Hine, R. C. (1991) 'Intra-Industry Specialization, Trade Expansion and Adjustment in the European Economic Space'. Journal of Common Market Studies, Vol. 29, pp. 603-22.

Greenaway, D. and Milner, C. (1986) The Economics of Intra-Industry Trade (Oxford: Basil Blackwell).

Grubel, H. and Lloyd, P.J. (1975) Intra-Industry Trade (London: Macmillan).

Helg, R., Manasse, P., Monocelli, T. and Rovelli, R. (1995) 'How Much (A)symmetry in Europe? Evidence from Industrial Sectors'. European Economic Review, Vol. 39, pp. 305-40.

Hine, R. C. (1989) 'Customs Union Enlargement and Adjustment: Spain's Accession to the European Community'. Journal of Common Market Studies, Vol. 28, pp. 1-27.

Hufbauer, G. C. and Chilas, J. G. (1974) 'Specialization by Industrial Countries: Extent and Consequences'. In Giersch, H. (ed.) The International Division of Labour (Tübingen: Mohr).

Isard, W. (1956) Location and Space-Economy (New York: Wiley).

Keeble, D., Offord, J. and Walker, S. (1986) Peripheral Regions in a Community of Twelve Member States (Luxembourg: Commission of the European Communities). Krugman, P. (1980) 'Scale Economies, Product Differentiation, and the Pattern of Trade'. American Economic Review, Vol. 70, pp. 950-9.

Krugman, P. (1991a) 'Increasing Returns and Economic Geography'. Journal of Political Economy, Vol. 99, pp. 483-99.

Krugman, P. (1991b) Geography and Trade (Cambridge, Mass.: MIT Press).

Krugman, P. (1994) 'Empirical Evidence on the New Trade Theories: The Current State of Play'. In CEPR Conference Report, New Trade Theories (London: CEPR).

Krugman, P. and Venables, A. J. (1996) 'Integration, Specialization and Adjustment'. European Economic Review, Vol. 40, pp. 959-67.

Lawrence, C. (1987) 'Product Diversity, Economies of Scale and International Trade'. Quarterly Journal of Economics, Vol. 98, pp. 63-83.

Marshall, A. (1920) Principles of Economics (London: Macmillan).

Neven, D. and Gouyette, C. (1995) 'Regional Convergence in the European Community'. Journal of Common Market Studies, Vol. 33, pp. 47-65.

Organization for Economic Co-operation and Development (1987) Structural Adjustment and Economic Performance (Paris: OECD).

Ottaviano, G.I.P. and Puga, D. (1997) 'Agglomeration in the Global Economy: A Survey of the "New Economic Geography"'. CEPR Discussion Paper, No. 356.

Pratten, C. (1988) 'A Survey of the Economies of Scale'. In Commission of the European Communities, Research on the 'Cost of Non-Europe, Volume 2: Studies on the Economics of Integration (Luxembourg: CEC).

Puga, D. (1996) 'The Rise and Fall of Regional Inequalities'. Discussion Paper No. 314, Centre for Economic Performance, London School of Economics.

Quah, D. T. (1996) 'Regional Convergence Clusters Across Europe'. European Economic Review, Vol. 40, pp. 951-8. 
Ray, E. J. (1991) 'U.S. Protection and Intra-Industry Trade: The Message to Developing Countries'. Economic Development and Cultural Change, Vol. 40, pp. 169-87.

United Nations (1961) 'Standard International Trade Classification, Revised'. Statistical Papers, Series M, No. 34 (New York: UN).

United Nations (1986) 'Standard International Trade Classification, Revision 3'. Statistical Papers, Series M, No. 34/Rev. 3 (New York: UN).

Venables, A. J. (1996) 'Equilibrium Locations of Vertically Linked Industries'. International Economic Review, Vol. 37, pp. 341-59.

Vona, S. (1991) 'On the Measurement of Intra-Industry Trade: Some Further Thoughts'. Weltwirtschaftliches Archiv, Vol. 127, pp. 678-700. 